\title{
Introduction: Understanding Security Sector Governance Dynamics in West Africa
}

\author{
Alan Bryden ${ }^{\star}$ and Fairlie Chappuis ${ }^{\dagger}$ \\ *Assistant Director and Head of Public-Private Partnerships Division at the \\ Geneva Centre for the Democratic Control of Armed Forces (DCAF) \\ ${ }^{\dagger}$ Programme Manager within the Research Division at the Geneva Centre for \\ the Democratic Control of Armed Forces (DCAF)
}

\section{The promise of good governance for security, development and democracy in West Africa}

If the post-cold war era brought new hope for development, security and democracy to the West African region, these hopes seem diminished in the first decade of the new Millennium. The burgeoning Nigerian economy may have shifted the economic centre of the African continent to the West African region, yet economic growth has not met the promise of a better future for a generation of young West Africans deprived of a sound education and relegated to a precarious existence in informal employment. While the pressures of frustrated development have not so far led to violent conflict on the scale seen in the 1990s and early 2000s, these tensions have still contributed to internal crises pitting insurgents, separatists and terrorists (as well as the forces of organized crime) against central state authority. Meanwhile the everyday security crises faced by populations as a result of rising crime and dysfunctional state security provision continue to hold back both the potential for economic development and the deepening of democracy.

While norms of democratic governance seem to have taken root in a number of countries, as reflected in the peaceful and orderly consolidation of

How to cite this book chapter:

Bryden, A and Chappuis, F. 2015. Introduction: Understanding Security Sector

Governance Dynamics in West Africa. In: Bryden, A and Chappuis, F (eds.) Learning from West African Experiences in Security Sector Governance, Pp. 1-18. London: Ubiquity Press. DOI: http://dx.doi.org/10.5334/bau.a. License: CC-BY 4.0. 
democracy in Liberia in 2011, Senegal in 2012, or Nigeria in 2015, reversals in Guinea in 2008, or Mali in 2012 also show that violent competition over the powers of state remains a threatening possibility. A clearer picture of these interrelated challenges is emerging, highlighting the ways that democracy, development and security are intimately interrelated. Thus the experiences of northern Nigeria and Mali as well as Benin, Niger and other states of the region have demonstrated how underdevelopment can cause immediate insecurity and threaten democratic governance. Moreover, these examples also show that what begins as a local, sub-national issue can rapidly escalate, engulfing the political centre of a state but also spilling across borders to become a regional threat. Similarly, instability that stems from elite power struggles at the apex of the state can quickly stall democratic processes, undermining state legitimacy and economic confidence necessary for development: Guinea, Guinea-Bissau and Côte d'Ivoire have all traversed such difficult periods in the first decade of the 2000s.

At a global level this disappointing record has been met with a volley of initiatives. The Millennium Development Goals recognised the relevance of poverty reduction to conflict prevention and these insights were built into international initiatives such as the New Deal for Engagement in Fragile States, which emerged over the following decade including 19 fragile or conflictaffected countries and eventually all OECD donor states (Busan Partnership for Effective Development Co-operation 2011; United Nations 2000; The Paris Declaration on Aid Effectiveness 2005; Accra Agenda for Action 2008; International Dialogue on Peacebuilding and Statebuilding 2011). The World Bank's 2011 World Development Report combined this political momentum towards a more holistic vision with the latest research on democracy, development and security, distilling these insights into an agenda for "security, justice and jobs" through more resilient, more legitimate institutions (World Development Report 2011). In 2015, this agenda has taken a further step forward in making inclusive, accountable institutions an explicit goal of the Sustainable Development Goals and linking this goal to conflict prevention and peace (Sustainable Development Goals 2015).

Governance has become the central concept at this confluence of democracy, development and security. Policy imperatives and scholarly research of development economics, conflict prevention and democracy have thus converged in the claim that the quality of governance can determine the trajectory of national affairs (see for example Halperin et al. 2010; Collier 2007). Seeking to apply these insights in the policy and practice of governance, such research has distilled a set of institutional qualities associated with progress in development, security and democracy under the term 'good governance'. While specific aspects of the good governance agenda vary between contexts and institutions, core elements include: accountability, effectiveness, efficiency, transparency, inclusiveness, equity and rule of law (Shabbir Cheema 2005). 
Applying the principles of good governance to the security sector is the goal of security sector reform (SSR). SSR aims to improve security for the state and the population by making security provision, oversight, and management more accountable and more effective within a framework of democratic control, respect for human rights and the rule of law (Bryden and Hänggi 2004; Hänggi $2003 ; 2004)$. In particular, applying the principles of good governance to the security sector emphasized the idea that the state could only enhance democracy, development and security if it were concerned not only with matters of national defence and state security but also with human security - freedom from fear for the population (Krause 2006). The concept of human security anchored the agenda for effective and accountable state security provision, management and oversight within a framework of democratic governance, respect for human rights and rule of law.

As a means of strengthening a legitimate state monopoly on the use of force, SSR tends to focus on institutions. North (1990) provided some of the earliest explanations for how institutions can support the delivery of public services, an insight on which Robison and Acemoglu (2012) built by underlining the importance of open-access institutions, while Fukuyama (2013) focuses on the capacity of a government to deliver on public services. If the entire spectrum of public sector institutions have roles to play in providing for democracy, development and security, the part of the state charged specifically with security provision, management and oversight presents special challenges. For this reason, the quality of security sector governance is especially relevant to the current challenges in the West Africa region and it is on these qualities that this volume focuses.

\section{Objectives of this volume}

The fact that the quality of security sector governance is crucial to the overall fate of democracy, development and security makes understanding the dynamics of good and bad governance in relation to the process of reform all the more important. This volume focuses on the nature of security sector governance in West Africa through the lens of particular moments and key agents of reform in six states of the region. ${ }^{1}$ It presents a collection of vignettes that together tell a larger story about the holistic nature of security sector governance and the dynamics of the reform process in a variety of unique national environments.

This volume differs from typical studies of SSR in that it does not seek to assess reform in its entirety as a longterm macro-national process; nor does it seek to develop an operational analysis of current security challenges. Instead this volume focuses on describing the fundamentally political dynamics of security sector governance and the need to understand these dynamics in the 
strategy, planning and implementation of SSR. The approach has not been to seek uniformity of analysis but rather to glean insights and perspectives from individuals whose proximity to the local context adds value. The contributors thus offer 'insider' perspectives based on personal background and experience. This has a number of implications. In particular, it is important to note that these accounts are not intended to provide a balanced view that weighs the pros and cons of different perspectives. Rather, they reflect the lived experiences, personal convictions and resulting biases of the contributors.

Security remains a taboo subject in many national contexts in Africa. In order to mobilise potential reform constituencies and build broad-based support for SSR there is a need to demystify the security sector. This requires a deep understanding of context. For this reason, the contributors place great emphasis on the political history that underpins current security sector governance dynamics. The key message is that for national stakeholders (and for external partners that want to support governance-driven SSR) acknowledging the deep historical currents that shape security at the national level is essential to understand opportunities and constraints for reform. These collected narratives are intended to generate practical lessons that can support learning and promote positive change. The fruit of these combined descriptions is thus an analysis of the larger patterns that emerge when these narratives are placed side-by-side, yielding insights for future approaches to SSR that are presented in the conclusion of this volume.

In focusing on micro-dynamics of reform, this volume posits a different understanding of what should constitute success and failure in security sector reform. In particular, this approach is innovative in acknowledging that the significance of specific moments and influential change agents will be fully visible only in retrospect. In the context of on-going political crises and even violent conflict, potentially transformational shifts will often appear isolated, superficial or insignificant. As a result, their potentially transformative character is neglected. Applying an approach that looks at change in a new way finds both successes and failures in unexpected times and places.

In adopting this approach, this volume also corrects a tendency in the literature to idealize conditions for success while neglecting the lessons of failure. Our approach reflects the fact that although examples of positive, transformational change are important, instructive insights also come from examples of reversal, stagnation or failed reform. Some narratives thus describe how reform faltered in a specific instance in the eyes of the local stakeholders. The focus for each chapter was selected in order to draw lessons from countries with diverse trajectories of political development: Ghana, Guinea, Liberia, Mali, Nigeria, and Senegal. This selection covers a range of contexts from democratic transition to consolidation, post-war and situations of democratic reversal. This range offers an instructive basis for comparison that incorporates insights from examples of progress as well as regression. 
In sum, the descriptions that constitute the bulk of this volume point to the usefulness of a methodological lens that shifts the focus from macro-national narratives to the micro-dynamics of institutional reform in the immediate political context. Through the eyes and experiences of local actors, this collection analyses the small-scale successes of SSR together with the missed opportunities that have prevented SSR from having more transformational effects. Based on narratives of potentially transformative moments of political reform by eminent national experts with personal experience of these reform processes, this volume shows how SSR efforts influence security sector governance dynamics in significant if limited ways, while drawing concrete and practical insights from these national reform experiences.

\section{Confronting a disappointing record: understanding the challenges of transformational change in West Africa}

Despite extensive effort and some progress, establishing more democratic security sector governance is an objective that most African countries find themselves far away from reaching. The complex interactions of history, politics and economics dictate the terms of security sector governance within the unique structural conditions of each national - and subnational - setting. Yet across the region certain shared experiences allow broader patterns to emerge from the descriptions collected in this volume.

Among the most decisive influences on security sector governance are the legacies of colonial and post-colonial statehood. While experiences of colonialism varied, the legacy of an extractive and illegitimate central political authority is a common one across many West African states. In this context the DNA of West Africa's security sector institutions has predisposed them to resource extraction and population control, and these characteristics have carried over into the modern context. Moreover, the experience of extraction and heavy-handed state authority may be the only vision of state security provision that a population and its leaders have ever known. Improving state security provision in such a social context is not a matter of technical reform, training or equipment: it is a matter of rethinking the raison d'être of state security providers from the bottom-up based on a completely new and different vision of what security means and in whose interest it is provided.

While the legacy of colonialism was carried over to West Africa's modern security institutions, these tendencies have been exacerbated by the region's incomplete democratization. As post-independence political regimes embraced patterns of illiberal governance, with extensive external support, they also fostered unresponsive and predatory security sectors focused on regime/state security. A lack of democracy enabled many of these regimes to endure for decades, permitting patterns of predation to become deeply entrenched. Legis- 
latures became beholden to powerful executives and judicial branches became the servants of state power instead of the rule of law. Under these circumstances, few states developed meaningful systems of democratic civilian oversight and national security developed into a domain of influence exclusively reserved for the most powerful political actors and men in uniform.

Even as state security sectors continued to serve the interests of the powers that be, populations took steps to provide for their own security. Commercial security provision became an immediate necessity for those that could afford it, while citizens without such means at their disposal turned to their own devices to protect themselves. Thus it came to be that despite the large and sometimes well-resourced security sectors at the disposal of West African states, the everyday security needs of a majority of the West African population were met by community-based non-state security providers or private security companies.

This context of economic hardship, social inequalities, and political disenfranchisement made fertile ground for armed conflict as social tensions spilt over into crime and political violence. States weakened by ineffective patronage-based political systems lacked the institutional capacity to respond effectively to the challenges with which they were confronted, and institutional and human capacity decayed further in the maelstroms that followed. As the legitimacy of state authority was eaten away by predation and ineffectiveness, the security sector became a further symbol of its illegitimacy as well as the hard edge of state repression.

\section{The emergence of the SSR approach}

The SSR discourse emerged in the late 1990s as a response to dysfunctional security sector governance and its consequences. Promoted first by European development agencies, SSR quickly became a pillar of multilateral strategies for crisis prevention, peacebuilding and development for organizations such as the United Nations, the African Union, ECOWAS, the European Union, the World Bank, and the OECD (United Nations Security Council 2014; African Union Commission 2013; Ball 2001; Aning 2004; Council of the European Union 2005; Council of the European Union 2006). While SSR is often perceived as an external agenda imposed on recipient countries, in particular in post-conflict contexts, this perception is inconsistent with the goals, principles and even history of SSR. The reasons for this are both pragmatic and normative. On the pragmatic side of the argument, reform strategies imposed from outside have repeatedly been shown to fail, because they are inappropriate to local context or not rooted in the local governance environment. On the normative side, the principles of good governance are inconsistent with the practice of imposed reform strategies. 
Moreover, history has demonstrated that the only sustainable shifts in the terms of security sector governance have occurred in the context of strong national leadership of the reform agenda: examples as diverse as Indonesia during the post-Suharto Reformasi era and South Africa in the postapartheid transition to democracy demonstrate the efficacy of strong political will for change (Cawthra and Luckham 2003). ${ }^{2}$ All of these insights make meaningful leadership and investment in reform by national and local stakeholders essential for sustainable improvement in security sector governance even if reform strategies in practice often leave much to be desired (Nathan 2007; Donais 2008; 2009).

Derived from an understanding of security based on the broader concept of governance, SSR brings together all actors with a stake in security provision, whether as providers, overseers or beneficiaries of security, and regardless of whether state or non-state actors (Chappuis and Hänggi 2013). This governance driven understanding of SSR also accounts for the fact that the holistic SSR concept can involve a broad range of activities from the development of more robust legislative frameworks for security provision, management and oversight, to reforms focused on specific security institutions such as police, military, intelligence or border authorities, as well as particular oversight bodies and functions, such as human rights commissions or ombuds-institutions, parliamentary bodies or the justice sector (OECD-DAC 2007; UN SSR Taskforce 2012; DCAF 2015; United Nations 2008; 2013). Moreover, SSR also recognizes that fact that experiences of security and justice are inherently linked and therefore includes the justice sector. This holistic understanding is the conceptual basis for a comprehensive approach to reform that considers all aspects of who uses force, how and on what authority. Indeed this very point is what makes SSR distinct from other types of security assistance or capacity development - SSR always aspires to improve both accountability and effectiveness. Reform that privileges one aspect in favour of the other would thus be inconsistent with the SSR concept (Chappuis and Hänggi 2009).

SSR began in different states across the region in the early 2000s as a response to the fundamental governance challenges typical of many states in West Africa. In Sierra Leone, Liberia, Guinea-Bissau and Côte d'Ivoire, SSR was variously attempted with significant international support in the context of the recovery from civil war (see respectively, Bryden et al. 2008; Albrecht and Jackson 2009). In Nigeria, Benin, Mali and Ghana, reform was initiated in the context of democratic transitions (see further Bryden and N'Diaye 2011). While SSR is not an agenda specific to Africa, many important cases have taken place there and West African states as well as the regional body ECOWAS have played a key role in developing the concept and practice of SSR. Good governance of the security sector underpins the Protocol relating to the Mechanism for Conflict Prevention Management, Resolution, Peacekeeping and Security (ECOWAS 1999), 
the Supplementary Protocol on Democracy and Good Governance (ECOWAS 2001), and the Supplementary Act and the Code of Conduct for the Armed Forces and Security Services (ECOWAS 2011) and later the Regional Framework on Security Sector Reform and Governance (ECOWAS 2014; see further, Uzoechina 2014).

The combined regional experience of reform has yielded several insights into typical characteristics of security sector governance in many reform contexts. While our concluding analysis expands in detail on these insights, at this stage it is sufficient to note that political will at the executive level is determinant in progress of reform (or at least disproportionately important). The overbearing influence of the executive in reform processes is linked to the fact that security affairs in general are often treated as a reserved domain over which few civilian politicians have any influence at all. As such securing the endorsement of the security elite for a reform agenda is a sine qua non of progress. The fact that the executive and the security forces maintain a tight hold over the reins of power and over security affairs in turn helps to account for the noticeable pattern of weak legislatures across the region. Whether lacking political authority or human and financial resources to fulfil their democratic mandate, weak legislative control and oversight of security affairs features in every country we examine. In some respects, strong civil society input can compensate for this deficit in formally representative oversight, and vocal and active civil society advocacy for better governance of the security sector is also a typical feature of many West African contexts.

\section{Neglected dimensions of security sector reform}

Against the backdrop of the failures in governance characteristic of many political systems across the region, it is unsurprising that SSR has not resulted in transformational change. As Hutchful and Luckham (2010) note, the promise of good security sector governance is very far from the reality in most African contexts and it for this very reason that meaningful SSR requires a radical transformational - change in the structures of power and governance of many states. This requirement for change in the most fundamental political, historical, and economic structures of governance in order to achieve the goals of good security sector governance has been said to constitute a "uniquely African dimension" of security sector reform, even meriting the term "security sector transformation" (Bryden and Olonisakin 2010).

Yet there is an obvious dissonance between the aspirations of the SSR agenda and the form it inevitably takes: Bryden and Olonisakin explicitly note, "security sector transformation, despite its radical overtones, is likely to be incremental and process-driven" (Bryden and Olonisakin 2010: 22). Despite this fact, current approaches to SSR are predicated on the idea that SSR can make 
profound changes to the conditions of governance over short time-frames and that the results of such reform strategies, when successful, ought to be obvious. This approach neglects that reality of change as a process, setting unrealistic expectations and emphasizing the least productive aspects of reform. The typical emphasis of many SSR strategies on training and equipping security forces while neglecting issues of democratic governance is a symptom of this problem. A more nuanced approach is needed to understand and assess SSR as an iterative and gradual process.

Acknowledging that SSR is a delicate and incremental process has implications for how we understand and assess the relative contribution SSR makes to democratic governance, peace and development. Taking the iterative nature of transformational SSR seriously requires a shift in focus in order to better recognize and weigh the potential long-term significance of incremental changes in the context of an on-going process. A new optic must be able to incorporate the idea that potentially transformational moments of reform are marked by shifts in the quality of security sector governance that are difficult to recognize as such at the time of their occurrence and may be easily reversed as the process develops in unforeseen directions.

Meaningful signs of change in the structural determinants of governance are small, smaller than approaches to SSR currently allow us to fully appreciate. This leads to neglect of the relative importance of small changes that can lead to long-term shifts, making it impossible to apply a flexible and adapted policy in response to the unfolding SSR process. There is truth to the claim that the goals of SSR are defined by a paradigmatic model of good security sector governance that no society on earth fully reflects. And on this basis, it must be acknowledged that all efforts at reform are found wanting and all measures of change are insufficient when held up against this idealized notion. This tendency to expect too much too soon also means that 'success' in SSR is defined by tangible or visible changes that often prove ephemeral and transitory in practice if they materialize at all. Current understandings of SSR are thus focused on spotting large shifts in outward appearance and overt practices rather than the small changes in norms, attitudes and expectations that may signal steps in the right direction.

Not only are signs of substantive change smaller than expected, they are also more likely to be literally 'invisible. Current approaches to SSR tend to emphasize visible changes in security provision from physical infrastructure and equipment through to new institutions or systems. This optic emphasizes the formal organizational character of governance which is often only a façade covering up the informal normative basis of security sector governance that defines the real "rules of the game" (North 1990). This point is not unappreciated in approaches to SSR and there have been some innovative attempts to improve on planning, design and assessment methodologies. Most notably these have integrated the dynamics of non-state security and justice provision 
into actor mapping and reform strategies, and also included more satisfaction and perception based tools in SSR assessments, relying on qualitative methods such as focus groups, interviews and perception surveys (see for example, CENAP/CREDESS-Bdi 2012; Schnabel 2009). While these innovations open intriguing pathways into the question of change in state security provision, too often actual reform strategy remains focused on the institutional impacts of top-down reform programmes.

A further neglected dimension in current approaches to SSR is the effect of exogenous and endogenous shocks. Thus, notwithstanding problems related to bad design, it is also clear that SSR frequently experiences setbacks and full reversals for unrelated reasons. Yet approaches to SSR have so far failed to coherently integrate the fact that SSR may be frequently subject to reversals in transition contexts (Chappuis and Siegle 2015). Considering the frequency with which SSR strategies are beset by endogenous setbacks in the domestic political environment or caught up in the consequences of external shocks, this is a striking exclusion. From a pragmatic point of view, being able to contextualize such setbacks and reversals is a precondition to recognizing possibilities for new openings. This neglected consideration also overemphasizes the relative gravity of reversals and failures, which studies have shown are a common occurrence in democratic transitions and conflict-affected states (see further Halperin et al. 2010; Haggard and Kaufman 1995; Przeworski et al. 2000; Collier 2010; Freunda and Melise Jaud 2013). A progressive view of reform instead requires that gains and losses be understood relative to the local security governance context and not idealized models of statehood that exist nowhere.

Focusing on local conditions of security governance is a further essential element in understanding the transformational potential of reform. In contrast to earlier neglected elements here outlined, the call to focus on local security governance is nothing new to the SSR agenda. Understanding the imperatives of local context as it is composed of local actors, politics, social context and history is essential to reform strategies and further underlines the necessity of local ownership in the SSR agenda. Yet an iterative understanding of SSR requires a much closer reading of local context than SSR specialists have thus far been prepared to make given the inherent limitations of external perspectives on domestic governance dynamics (Schroeder et al. 2013). As a result, the study of SSR processes has been heavily skewed in favour of external analyses of reform contexts that compare superficial changes in security organization or structure with the idealized western model. In order to get beyond the limitations this bias imposes, analyses of reform contexts are required that bring to bear an intimate knowledge of history, social, economic and political context. Local voices, local perspectives can help to correct the bias towards unrealistic expectations that externally driven approaches to SSR have inadvertently created. 


\section{Iterative, gradual: reframing the analysis of SSR in West Africa}

From this critique of current approaches to SSR follows logically the need to develop an analytical perspective on SSR in West Africa that can capture the potential for iterative and gradual change. In order to properly assess the relative importance of change, a description of the balance of power among various actors within and beyond the security sector is necessary. Such a description must also encompass the structural context within which SSR takes place and which determines security sector governance. This in itself is not a new approach - guidance on SSR always points to the relevance of contextual analysis and actor mapping (see for example, OECD-DAC 2007). In this volume our contributors offer the necessary descriptive elements for such an analysis by focusing on specific moments of change that may reveal something important about the immediate context at stake and the process of reform in general.

Turning first to the structural determinants of security sector governance, the potential for change must be understood against the backdrop of complex interactions between existing political, social, economic and historical trends, which in concert create what Schnabel and Born (2011) define as permissive and non-permissive reform environments. The interweaving of these diverse influences gives rise to the irreducible complexity of governance contexts that defies all but the broadest categorisations. It is precisely because each reform context is highly complex and therefore unique that understanding security sector governance requires an investment in exhaustive description. The complexity of interwoven governance dynamics also provides a rationale for focusing more attention on the micro-patterns of reform since it is at the level of inter-institutional and interpersonal interactions that complexity can yield to useful description. Such description provides a basis for comparative analysis to carefully assess what these patterns of interaction at the micro level might imply for the practice of reform in general and to what extent the findings may or may not be applicable in other contexts.

Where the existing political, economic, social or historical conditions remain stable, there is little room for reform to generate outcomes outside the existing status quo. However, where these structural conditions soften, new outcomes become possible. A typical example of a softening in structural conditions facilitating reform is a case of post-war transition where the influence of traditional power brokers is weakened and new actors have yet to impose themselves: in the uncertainty of the post-war phase new influence can come to the fore. Yet the status quo in an apparently stable situation can also be unexpectedly disrupted when a particular - even apparently insignificant - event catalyses action that can change the underlying situation. In the narratives here presented these dynamics become evident where, for example, a sudden trigger event makes a radical rupture with prior practices possible or even necessary. In the new 
status quo that emerges following such cathartic episodes, reform may progress or regress; in several of the narratives such trigger events were defining moments in reform processes, setting in motion processes of potentially transformational change. In order to capture the complex dynamics of the structural constraints that define security sector governance in the examples we study, each of our contributors takes the time to recount their own perspective on the most important social, political, economic and historical factors influencing the state's provision of security.

If the structural determinants of security sector governance are the playing field on which political competition over reform plays out, then the moments when competing agendas clash are the defining events in the reform process. These events may be small, even apparently banal changes that come to affect how power is exercised. A decision, a new practice, a policy shift, a change in attitude: such moments of reform can turn out in retrospect to be the foundation for decisive changes that over the long term amount to a transformational effect. At this level of small-scale moments in the reform process, change may come swiftly once the right conditions materialise. Indeed this speed may be matched only by the rapid deterioration that is possible in moments when the status quo destabilizes. Such moments of rapid change create the basis for a new status quo, which will either reinforce and enhance or undermine and prevent progress towards better security sector governance. The continuing succession of such moments defines the overall trajectory of the reform process.

In these decisive moments, specific actors, especially among the powerwielding elites in politics and the security sector, can play a disproportionate role in forcing change for the worse or for the better. Where the status quo remains intact, specific actors may apparently have little room for manoeuvre in influencing the determinants of security sector governance. Yet these conditions can change and sometimes quite quickly, especially when a number of actors come together in a coalition that is sufficient to disrupt the usual practices upholding the dominant status quo. This dynamic has been noted in analyses that point to the relevance of building so-called "inclusive enough" reform coalitions (World Development Report 2011: 120). In the narratives we present here this dynamic was illustrated by the surprising degree of influence that civil society could bring to bear on otherwise insensitive and inflexible regimes. Similarly, the most decisive factor in whether reform would advance or stall was in several examples the positive or negative disposition of top-level leaders in government. Moreover, words alone were often the only instrument these actors used to influence the process one way or another, illustrating the underrated value of dialogue in reshaping security sector governance. To capture this aspect of influence, our contributors pay special attention in their narratives to identifying the champions and spoilers of reform and how their actions defined the crucial moments of the reform process. 
If the agency of specific individuals can have a defining influence on the nature of the reform moment, such agency is conditioned by the context within which such individuals operate and will define the room to manoeuvre at their disposal. Yet besides agency, contingency can also be an important driver of change or guarantor of the status quo. Although there is a prevailing tendency to think of reform outcomes as the intended result of planned interventions on the part of specific (too often external) actors, plans may go awry and in complex environments usually do. As a result unintended consequences or accidental interactions can determine the process of reform, its context and outcomes. For this reason a fuller understanding of SSR must make analytical space for contingent, accidental, and unintended effects which often occur at the micro-level. In this volume, authors have traced the logic of reform interventions in each narrative but have also pointed out the many unintended, accidental and contingent effects that decoupled these plans from their intended consequences. This approach has offered nuanced insight into why reforms stalled despite the best efforts of reform champions or advanced in spite of the influence of reform holdouts.

It should be obvious at this point in the discussion that a full account of the reform process requires a profound knowledge of the political, social, economic, and historical context within which it occurs. Not only is it possible that the minutest details of actors or context prove determinant in explaining how reform progresses or not, but perspectives on which details matter most may differ markedly based on knowledge of context. National narratives founded on local expertise and perspectives provides a feel for context that cannot be matched by external specialists, offering potentially new purchase on questions that external analyses have so far failed to adequately account for. This approach is promising because relatively few contributions on SSR in Africa have been authored by experts from the region or nations concerned (see for example Uvin 2009; Malan 2008; Greene and Rynn 2008; Albrecht and Jackson 2009). As a result of this external story-telling, the literature is skewed towards external perspectives on reform that are heavy on technical details and light on political, social and historical context (for important exceptions to this trend, see Bryden and Olonisakin 2010; Bryden and N'Diaye 2011; Bryden et al. 2008).

In contrast, the narratives collected in this volume are the work of a diverse group of individuals drawn from among the research, political and security communities of each country. In describing each context from their own personal point of view, contributors bring to bear all the benefits of direct insider experience as well as a profound knowledge of history, society and politics. These experts have experienced first-hand the processes of reform which they narrate. Their accounts represent personal vignettes in the tradition of thick description, rather than formal analytical case studies in the conventional social science tradition. Their status as national experts themselves embedded in the particular 
social and political context in which reform unfolds gives them privileged analytical access to perspectives invisible to external points of view, no matter how well versed in subject matter or how familiar with local dynamics. At the same time, this analysis cannot be detached from the authors' own perspectives, experience and predispositions. For all these reasons, these chapters constitute authentically national as well as personal accounts of reform dynamics.

The contributors to this volume focus on the institutional dynamics of security governance and the nature of state security provision. Turning first to institutional dynamics of security governance, it is clear that transformational SSR implies a shift in the balance of power between the relative parties in government; the relationship between the security sector and civilian power; the balance of power between civilian control bodies; and, the dynamics of control and responsiveness between the state and the population. That the governance aspects of reform are laid aside in favour of more short-term, so-called technical reforms is an oft-cited complaint about the formulation of SSR programmes. As a result a number of the narratives collected here focus explicitly on aspects of institutional governance, even though efforts at SSR in these countries are more often associated with ambitious 'train-and-equip' style programmes: for example, T. Debey Sayndee throws new light on the SSR process in Liberia by examining SSR through the lens of legislative developments in a case that is usually treated as an example of police and military reform. Similarly, Emmanuel Kwesi Aning focuses on the little-known example of the revival of the Police Council in Ghana where more attention has tended to centre on the reform of the Ghanaian Police Service itself. Looking at the transition from military to democratic rule in Guinea, Dominique Bangoura describes in detail how reform minded military actors aligned with civilian politicians to rearrange the balance of power - both formal and informal - between the armed forces and a newly elected democratic government.

The second aspect of potentially transformational moments in security sector governance and reform on which our authors focus is the nature of state security provision. From the perspective of good security sector governance, state security provision should address security from the point of view of the population by focusing on the character, accountability, effectiveness and efficiency of organizations charged with the use of force on behalf of the state, as well as how the state meets its responsibility to monitor and control the use of force. These are the aspects of reform that are most likely to reflect short-term changes (though not necessarily positive ones) by the simple fact that the functions of security institutions are most often the entry-point for reforms. In our collection of narratives, E. Remi Aiyede and Zeïni Moulaye show how the poor interface between management, control and performance laid the foundation for the operational failures of the defence forces in Nigeria and Mali respectively. In contrast, General Lamine Cissé offers a personal perspective on how the defence forces in Senegal have in his view escaped politicisation even while 
facing the dual pressures of an on-going internal insurgency and a delicate consolidation of multiparty democracy. In diverging from alternative accounts of the conflict in Senegal in particular as concerns respect of human rights and treatment of the civilian population, this chapter also illustrates the distance that remains to be bridged between between internal and external perspectives.

An important facet of these narratives is that they do not only consider change for the better. Several contributions document how a potential opening towards reform and improved governance was stalled, stymied or sabotaged by vested interests or accidents of the process: Aiyede details how corruption and vested interests bled momentum from the process of defence reform in Nigeria, while from Mali Moulaye recounts the political manoeuvring that transformed a comprehensive and holistic reform strategy into a dead letter ultimately contributing to the conditions for national crisis which followed in 2012.

The conclusion to this volume presents the lessons to be learned for SSR based on insights from a comparative analysis of these rich descriptions. As such it argues for the relevance of focusing on reform processes as an iterative and gradual evolution in the dynamics of security sector governance. This perspective can reveal developments that may otherwise go unnoticed - both positive and negative - at the national, sub-national and local levels. A detailed explanation of the dynamics of reform can then allow for strategies that are better calibrated to local context while establishing more productive reform priorities. Applying this analytical approach will allow us to draw further lessons from the extensive experiences of the West African region in SSR and to think differently about how to support reforms aimed at improving security sector governance.

\section{Learning from West African experience in security sector governance}

In bringing together six eminent experts to describe moments in the long trajectory of their national reform processes, this volume offers a unique take on experiences of reform in each national context. Each of our authors thus focuses on specific moments of policy shift that have led either to a qualitative change in some aspect of security sector management, oversight and control or to a change in the nature of security provision. The approach places particular emphasis on describing how the momentum for or against reform emerged in each unique situation.

Chapter 2 considers the resurrection of the Police Council in Ghana in 1992. Ghana is often cited as a regional example of democratic transformation and improved security sector governance, yet the roots of this transformation remain poorly understood. Filling this gap in the historical record of Ghana's democratic governance, Aning examines the 1992 resurrection of the Police 
Council and its patchy track record as an organ for democratic oversight and police management before and since this turning point. Tracing its origins in the first era of Ghana's democratic independence through long periods of neglect under military dictatorship and its eventual resurrection under the constitution of 1992, Chapter 2 demonstrates the usefulness of looking for progress in democratic transformation within the micro-dynamics of a much larger, much longer, reform process.

Chapter 3 looks at the political transition in Guinea. Guinea's long and tortured history of military rule left little hope for the future when a young and inexperienced soldier seized power abruptly in 2008. Yet against this bleak background, a democratic transition has slowly emerged under the guidance of a reform-focused military leader who bridged the civilian-military divide building trust and the basis for a new political era. Focusing on Guinea's delicate political transition during the period of 2009-2010, Bangoura traces Guinea's difficult path back to civilian government and democratic civilian control of the security sector.

Chapter 4 considers the neglected question of legislative governance in Liberia's post-war reform experience. Despite 133 years of unbroken civilian government, one of Africa's oldest independent republics nevertheless suffered from grave democratic deficits in legislative governance throughout its history. Following two decades of military rule and devastating conflict, Sayndee charts the rise of the Liberian legislature and its unprecedented role in establishing an entirely new legislative framework for democratic governance of the security sector in the context of Liberia's long struggle to recover from civil war.

Chapter 5 dissects Mali's record of reform in an era of democratic transition. Slated as the paragon of transformational reform and peaceful conflict prevention in the 1990s, Mali's sudden democratic reversal and subsequent armed conflict surprised many in 2012. Although the state of Mali's security sector has been the subject of much scrutiny since the dramatic events of 2012, Moulaye looks back to earlier attempts at comprehensive SSR in the 2000s, finding the roots of a future crisis in past failures to tackle reserved domains in the defence sector.

Chapter 6 relates the promise of Nigeria's transition to democracy, which seemed to augur a new era of democratic security sector governance. Yet the country's security forces failed to throw off the shackles of dysfunction and corruption leading to dramatic failures in security provision and national defence in the face of a vicious internal insurgency. Against the backdrop of Nigeria's contemporary security challenges, Aiyede explains how Nigerian attempts at SSR over the period 1999-2007 were able to snatch defeat from the jaws of victory.

Chapter 7 presents Senegal's unique regional experience with civil military relations. Senegal's long history as a consolidated and peaceful democracy stands in contrast to the experiences of many states of the region. And all the 
more so because Senegal has succeeded in consolidating its democracy while isolating its security sector from the same destabilizing effects of internal armed conflict that have brought low many of its neighbours. Cissé presents his own insider perspective on the foundations of democratic civilian control in Senegal as West Africa's oldest democracy marks its first democratic alternance in a new era of multi-party politics and even as one of the world's longest-running internal conflicts continues in the Casamance region.

Despite the wide range of national contexts covered across these chapters, a number of commonalities are nevertheless evident. Legacies of authoritarian governance have left behind specific security cultures with common features across all six contexts. This is evidenced by the fact that security is treated as a taboo area reserved for security professionals, or a little more broadly, elite politicians. These habits of interaction also contribute to cultures of adversarial relations between security forces and the political executive, between the political executive and other branches of government, and between government and the wider public represented by civil society. Moreover, there is limited tradition of discussing security issues beyond narrow elites. This reflects a focus on regime security, and the history of security institutions as defenders of state power. These characteristics have several direct consequences for SSR, which are brought out in the comparative analysis that concludes this collection in Chapter 8.

After a decade and a half of targeted support and sometimes heavy-handed interventions, the results of SSR processes have to date proven mixed at best and it is clear that things have not worked out as once was hoped. The challenges that SSR seeks to address can be summarized in the failure to tackle the dysfunctional patterns of security governance that maintain status-quo power relationships and undermine the legitimacy of the state as a provider of security. While the inherent complexity of security sector governance within a given national context is an important reason why SSR has not resulted in transformational change, the conclusion to this volume argues that the lack of an analytical perspective attuned to recognise iterative and gradual evolutions in governance has contributed to this failure. The narratives that follow seek to remedy this deficit by providing granular, insider descriptions of slow and unsteady change in West African experiences in security sector governance.

\section{Notes}

${ }^{1}$ In its references to moments of change and the relevance of individual actors within sequential processes of institutional evolution, the analytical approach applied in this volume draws on historical and sociological theories of institutionalism. For key references in this literature please see further Hall and Taylor (1996); March and Olsen (1983); Peters (2011). 
${ }^{2}$ While both Indonesia and South Africa constitute examples of strong national leadership, it should be noted that in both cases the record of reform in the post-transition era was subsequently challenged as a failure to adapt to the core normative concept of SSR by applying the principles of good governance to the security sector. For alternative views see further Baker (2015); Altbeker (2005). 